além dos textos, ao empreender a produção prática do direito.

Por isso tenho insistentemente afirmado inexistirem soluções previamente estruturadas, como produtos semi-industrializados em uma linha de montagem, para os problemas jurídicos. $\bigcirc$ trabalho jurídico de construção da norma aplicável a cada caso é trabalho artesanal. Cada solução jurídica, para cada caso, será sempre, renovadamente, uma nova solução. Por isso mesmo - e tal deve ser enfatizado - a interpretação do direito se realiza não como mero exercício de leitura de textos normativos, para o que, repito-o, bastaria ao intérprete ser alfabetizado.

6. Presta-se essa minha breve digressão a explicitar, e também fundamentar, a afirmação, que faço, de que, tal como ocorre em relação às decisões judiciais, a solu- ção atribuída pelos juristas, em seus pareceres, a cada quesito que lhes tenha sido proposto é resultado da interpretação dos textos e de determinada situação de fato (= de determinados fatos).

Distintos os fatos, outras serão as soluções (= normas jurídicas) a serem a eles aplicadas, ainda que desentranhadas dos mesmos, exatamente dos mesmos textos normativos dos quais foram desdobradas as primeiras soluções consideradas.

É a capacidade de discernir essa circunstância que faz o jurista e permite a contínua renovação da força normativa dos textos, diante da perplexidade dos apedeutas.

Aqui não é a caravana, mas o direito que passa - e não ao som de latidos, mas de algo assim como a canção de JOAQUÍN SABINA, "pior para o sol"!

\section{As Diversas Eficácias e seu Convívio no Conteúdo da Sentença. A Tese de Pontes de Miranda}

\author{
Fexnanda Pa \\ Advogado em Porto Alegre.
}

"Há expressões comuns a essas cinco situaçôes: a primeira situação é a mesma que era, daí dizer-se é ou não é; a segunda faz existir algo que não existia, ou deixar de existir o que existia; a terceira afirma que houve ou não houve, e impõe que não haja; a quarta resulta de ato de alguém que não a fez, porém mandou que se fizesse; a quinta faz passar o que existe a outro lugar onde não existia, porque at é que devia existir. (Pontes de Miranda)
0. Quando JULIUS HERMANN 17. VON KIRCHMANN, em 1847, pronunciou sua conhecida e cáustica conferência, "Jurisprudência não é Ciência", em sociedade jurídica berlinense jamais identificada, e na qual negou caráter científico à jurisprudência, não poderia ter-lhe passado pela cabeça, naquele momento, estivesse a sacudir, tão intensa e extensamente, com a ciência do direito, nem tampouco estivesse - e isso é para nós aqui e agora o mais expressivo - a bulir num de seus mais sensíveis pontos, qual seja, o do uso da linguagem e o sentido das palavras havido pelos doutrinadores do direito, sem o rigor técnico necessário, de modo a refletir, na conceituação de institutos jurídicos, maior precisão taxinômica, a lhes emprestar foros de cientificidade.

Essa imprecisão conceitual faz-se, por exemplo, particularmente sensível no tocante ao que se compreende, a rigor, por eficácia da sentença. $\mathrm{O}$ tema vem preocupando os mais doutos processualistas nacionais, sobretudo pela sutileza com que a palavra eficácia é usada e, conseqüentemen- 
te, compreendida - sem normas ainda definidas e suficientemente abrangentes de seu emprego pela comunidade jurídica -, com diferentes conotações no contexto de discursos doutrinários em que é empregada.

Daí surgem não pequenos problemas, tais como o de questionar-se se a sentença contém uma só ou várias eficácias? Como conviveriam elas - caso seja admitida a hipótese de serem várias, como defendeu o insigne jurisconsulto pátrio, PONTES DE MIRANDA -, no conteúdo da sentença? Assistir-lhe-ia razão no atribuir diversas eficácias a uma só sentença? Em que medida poderia ser aceita sua tese, inclusive no tocante à chamada "constante 15 "?

02. Tecer considerações ou comentários à obra de um mestre, a mais das vezes é obra espinhosa e delicada. Sobretudo torna-se mais ingente o esforço interpretativo, quando ele mesmo reconhece que o tema sobre o qual versa tem levado à perplexidade estudiosos "da mais alta ciência", devido serem recentes as indagações a respeito do assunto.

Realmente, tendo sido passados 60 anos, quando PONTES DE MIRANDA teve a extraordinária intuição que o levou a "descobrir" a existência das cinco categorias determinantes de sua teoria quinária das ações, ainda hoje recorrentemente se debate o preciso conceito de eficácia da sentença e de seus diferentes efeitos.

PONTES DE MIRANDA, teve a intuição - que BERGSON, reconhecido pelo inusitado e singeleza de suas expressões, denominava la pensé durée, ou a simpatia espiritual - em 1939, quando entre nós predominava incontestada a doutrina processualística européia, de forma marcante a italiana. Não obstante, e relevando a possibilidade de outros a terem visto, foi ele quem, de fato, a enxergou, quem sentiu a cultura histórico-jurídica nacional daquele instante, para quebrar um paradigma, o da classificação trinária das ações, que se fazia clássico, e criar outro novo, o da classificação quinária, mais consentâneo à realidade do logos nacional.

Sem dúvida, apercebeu-se ele antes e melhor do que ninguém o poder de que está investido o juiz no ordenamento legal brasileiro, fruto que é do acentuado ecletismo intelectual pátrio, sempre a retirar e de aproveitar tudo aquilo que se apresenta como de mais conveniente e mais adequado em diferentes correntes doutrinárias alienígenas, mesclando os elementos e os adaptando às circunstâncias peculiares de nossas exigências culturais do momento.

Assim estava mergulhada a cultura jurídica do país, desde os idos da proclamação da República e da primeira constituição republicana de 1891 - cujo anteprojeto fora elaborado por RUI BARBOSA -, im pregnada por um ecletismo onde se fundiam as influências doutrinárias européias, sobretudo a da separação dos Poderes sob a inspiração de MONTESQUIEU, e a doutrina americana dos Founding Fathers - ciosos dos direitos fundamentais do homem donde o jurisconsulto trasladou o habeas corpus e aderiu, dentre outras, à idéia prevalecente de que o Supremo Tribunal Federal é "o guardião, o intérprete e o oráculo" da Constituição Nacional. Demais, filiou- se ao sistema inglês da common law, ao não admitir o contencioso-administrativo - ao contrário do que ocorre no direito continental europeu - ao mesmo tempo em que ampliou superlativamente o exercício da jurisdição.

Essa, pois, era a mentalidade jurídica da época, quando PONTES DA MIRANDA teve o pioneirismo genial de classificar as ações e as sentenças de acordo com a eficácia com que um dos cinco elementos: declarativo, constitutivo, condenatório, mandamental ou executivo, correspondentes aos cinco verbos em que a parte pede seja satisfeito seu interesse jurí dico, haveria de erguer-se. Ademais, sempre um, preponderantemente, com maior força, no conteúdo sentencial.

PONTES DE MIRANDA apercebeu-se de algo que sempre estivera obviamente presente em nosso ius positum, mas de que não se deram conta os juristas da época, como a comprovar o que KARL MANNHEIM dissera acerca de o indivíduo propriamente não pensar, mas tão-somente participar, com maior ou menor genialidade, do pensar de seu tempo. PONTES DE MIRANDA teve, indiscutivelmente, o sapere audet do gênio que foi.

Àquilo que intuíra e que ao longo de cinqüenta anos de sua existência vinha empiricamente comprovando, ARAKEN DE ASSIS, em meados da década de 80 , procurou dar foros de cientificidade, utilizando-se, para tanto, do princípio da falseabilidade de KARL POPPER, a fim de demonstrar que a teoria trinária da classificação das ações e das sentenças, então clássica e incontestada, não resistiria à comprovação do teste da refutação, pois de fato existiam, além das ações declaratórias, constitutivas e condenatórias, mais duas: a mandamental e a executiva, que espontaneamente brotavam das necessidades práticas do cotidiano jurídico nacional, a exigir classificação adequada.

Todavia, se hoje, salvo honrosas e distinguidas exceções, a maioria superlativa da doutrina brasileira aceita e abraça a teoria quinária da classificação das ações e das sentenças em declarativas, constitutivas, condenatórias, mandamentais e executivas; pacífica não é, porém, a conceituação de eficácia da sentença; de seus efeitos, nem tampouco é tranqüilo a existência de diversas eficácias, convivendo no conteúdo das sentenças.

Procurar determinar o que PONTES DE MIRANDA entende por eficácia e por efeitos, e, em particular, o preciso significado com que usa tais palavras não se constitui em fácil tarefa.

03. Começaremos por tecer algumas considerações a respeito da teoria quinária desenvolvida por PONTES DE MIRANDA, sob o viés particular ao tema deste ensaio.

Para tanto, e a fim de não nos desviarmos da linha de raciocínio do eminente jurista e, ao mesmo tempo, alcançarmos o objetivo de responder às indagações objeto deste estudo, é que nos manteremos o mais próximo possível da terminologia por ele adotada em sua exposição doutrinária, em especial o Tomo I, Ação, Classificação e Eficácia, do "Tratado das Ações".

No início do Capítulo II, da Parte II, da classificação das ações, ao abordar a pre- 
ponderância da eficácia, já emite opinião que permeará todo seu Tratado: (sic) "uma coisa é a força da sentença - eficácia preponderante - e outra a eficácia imediata ou mediata, sem se falar nas duas menores com que se completa a constante da eficácia das ações e das sentenças".

Já aqui se é apresentado a quatro idéias distintas, cujo significado é de máximo mister ser ressaltado e plenamente entendido, como chave para a compreensão maior do conceito de eficácia lato sensu. Primeiro, a idéia de uma força que se constitui em eficácia preponderante. Segundo, a idéia de eficácias adicionais àquela preponderante, imediata e mediata. Terceiro, a de existirem, além destas duas últimas eficácias, outras de menor monta, ou melhor dizendo, de menor peso. Finalmente, a idéia da existência de uma constante.

Como se vê, há um prius a se impor para o bom entendimento da exposição e que pode ser resumido em uma curta frase: para o nosso autor não existe ação ou sentença em estado puro, isto é, com uma só eficácia.

Isso assim colocado, passo seguinte é o de se entender que toda ação ou sentença carrega em si mesma, no bojo do projeto de provimento jurisdicional esperado, por quem pede ao Estado a satisfação de seu interesse ofendido, existe uma carga maior, uma eficácia maior, preponderante, sobre as demais provisões satisfativas de direito material contidas na sentença. Desta forma, em toda ação declaratória a eficácia maior é a de declarar. Na constitutiva, é a de constituir; na condenatória, a de condenar; na mandamental a de mandar e, na executiva, a de executar. Eis, os cinco verbos que emprestam à cada ação ou sentença sua força ou eficácia preponderante.

A partir desse ponto, porém, a compreensão do modo como surgem as eficácias imediata e mediata, complica-se sobremaneira porque PONTES DE MIRANDA, para explicar como isto acontece, em seguida à força da sentença, introduz no discurso uma nova noção impregnada de subjetivismo, inclusa na idéia de peso.

E isso porque, segundo ele, v.g., na ação declaratória (sic) "mais se quer que se declare do que se mande, do que se constitua, do que se condene, do que se execute". E a seguir completa, "No seu peso de eficácia aparece 4 na coluna da mandamentalidade; é a chamada eficácia imediata, a eficácia que vem logo após, como peso, à força mesma da sentença (grifos nossos)". E assim, respeitante o tipo de ação, a eficácia preponderante, inclusive a imediata e a mediata, apareceria, em bloco, embora com pesos distintos, sempre de 1 a 5 . A execução de mão própria, apenas para dar outro exemplo, seria do tipo: $3,2,4,1,5$ (!).

Evidentemente há nisso um enorme grau de arbítrio. Quer parecer que PONTES DE MIRANDA, neste ponto, deixou de se interessar pelo que é, para concentrar-se no modelo matemático, ou seja, naquilo que pretende ser.

Contudo, a rigor, não há matemática no modelo, mas arbítrio, e, neste prisma, uma ação declaratória, para ser eficazmente declaratória, deve ser declaratória em primeiro lugar, com peso 5 , depois mandamental com peso 4; depois constitutiva (3); depois condenatória (2); depois executiva (1). Uma ação constitutiva deve ser constitutiva primeiro (5), depois declaratória (4), depois mandamental (3) e assim sucessivamente.

A idéia de peso, por conseguinte, explica-se unicamente pela forma como a ação é descrita na ordem natural ou preponderante desses qualificativos, declaratório, constitutivo, condenatório, mandamental e executivo. Tudo soma 15 , porque a ordem é sempre: $5,4,3,2,1$, tout court.

Como a se dar conta do excesso de arbítrio por ele cometido em formular seu modelo, passo seguinte, já ao tratar no § 27, sob a rubrica - Medida da Eficácia Imediata e de Eficácia Mediata - PONTES DE MIRANDA ameniza o tom e diz (sic) "se a sentença favorável preponderantemente declara, provavelmente, contém mandamento com eficácia imediata, ou mediata" (grifou-se). E, da mesma forma (sic) "se a sentença preponderantemente constitui, provavelmente, ou declara em peso imediato ou com peso mediato manda" (grifouse). O mesmo apontando nas três demais categorias de ações.

Ora, provável, é a demonstração imperfeita da verdade procurada. Como não existe um critério geral de verdade unanimemente reconhecido, fica-se, pois, com a verossimilhança, ou seja, com uma situação que provavelmente mais se aproxima da verdade, do que de outra, menos verossímil.
Não obstante, ter aparentemente arrefecido o grau de arbítrio, PONTES DE MIRANDA retoma linhas a seguir 0 diapasão anterior e afirma que todas as ações, tanto quanto todas as sentenças, teriam, além de uma força ou de uma eficácia preponderante, uma eficácia imediata e uma mediata, como também outros elementos mínimos, "inelimináveis", para perfazer a soma constante 15 .

A tese da existência de pesos com soma 15 , constante em toda a sentença, nada acrescenta à inteligibilidade do tema. Não se pode deixar de prestar homenagem a um mestre do porte de PONTES DE MIRANDA pela originalidade, mas, nesse ponto, que nos perdoe o jurista, errou com o mesmo brilhantismo como somente aos gênios é desculpado errar.

04. É à altura da exposição da teoria quinária das ações, que PONTES DE MIRANDA passa a examinar em particular "sentenças e eficácia".

Após conceituar a sentença como a prestação jurisdicional, objeto da relação jurídica processual, para a realização de seu conteúdo, dela sentença, acrescenta que, para falar-se de eficácia, "tem-se de cogitar de força e efeitos, porque eficácia é a propriedade de ter força e efeitos".

Oautor, portanto, introduz duas novas noções: conteúdo e efeito, das quais também passaremos a tratar, em conjunto com os conceitos de força e de eficácia das sentenças: imediata, mediata e mínima.

Mas a partir daqui nota-se que a teoria quinária da classificação das ações e, corolariamente, das sentenças, até então 
linearmente tratada, entra em zona obscura e a visão clara de horizonte resta obnubilada por nuvens um pouco pesadas, senão negras. Duas páginas adiante, em nova guinada na linha mestra de sua exposição, afirma o jurista que a eficácia "é a energia automática da resolução judicial...(omissis)...(compreendendo), portanto, a força (e.g., a eficácia consistente na força de coisa julgada material da sentença declarativa) e o efeito (e.g., a eficácia consistente no efeito da execução da sentença condenatória, efeito que as sentenças declarativas não têm)" (grifos do autor).

Portanto, ao que antes se pressupu nha cristalino, em conviverem no conteúdo da sentença várias eficácias, embora com pesos distintos, agora, pelo visto, existe uma força, isto é, uma eficácia preponderante, e, no lugar da eficácia imediata e mediata surge também a idéia de efeito, que, tanto quanto a força, são, segundo ele, "duas classes de eficácia" (!).

E, assim como as ações são classificadas quanto à qualidade de serem declarativas, constitutivas, condenatórias, mandamentais ou executivas, também as sentenças o são, pois que "nenhuma, que se conheça, é sempre pura, isto é, com um só elemento" (grifou-se).

Dessarte, diz o autor, "não há outro meio científico, de classificar as sentenças, que por sua força, pesando-se-lhes, por bem dizer, a eficácia (força e efeitos)" (grifouse), e logo adiante, no parágrafo seguinte, torna a afirmar que "A classificação em cinco categorias atende à preponderância dos elementos (à força), porque, se tivéssemos de atender a todos os efeitos, desceríamos a casuística".
Quanto mais se refere o eminente jurista às forças e aos efeitos que servem para classificar as ações e as sentenças, ou, ao que aí importa, no problema da eficácia, ou seja, o de saber qual a força preponderante à cada classe, "admitido, como observa, que renunciamos a classificação das ações das sentenças pela força única de cada uma" e, sobremaneira, quando na p. 179 da obra comentada, apresenta-nos a tabela dos elementos das ações, a fim de concluir que, para cada classe de sentença, seja ela declarativa, constitutiva, condenatória, mandamental e executiva, com uma força declarativa, constitutiva, condenatória, mandamental ou executiva, acrescidas de elementos (efeitos), em ordem variável (subtraindo-se o da força qualificativa), em declarativa, constitutiva, condenatória, mandamental e executiva, a imprecisão formal do pensamento e as oscilações da linguagem, provocam confusão no leitor diante do turbilhão das idéias lançadas no texto.

A esta altura da exposição não se tem mais como perfeitamente entendido se, na força da sentença, que antes correspondia à noção de eficácia preponderante, incluise do mesmo modo a eficácia imediata e a mediata, e as mínimas; ou, se, ficaram estas englobadas entre os efeitos, uma vez que, pelo visto, efeito é uma classe de eficácia, que vinha em seguida à força, a fim de constituírem ambas a eficácia propriamente dita. Ademais, o elemento que anteriormente servia para qualificar e classificar as ações e as sentenças em cinco categorias, como força preponderante, agora, todavia, passa a ser apresentado também como efeito.
Nem por isso faz-se menos obscura a exposição daí por diante, para que afinal aponte o escritor critério objetivo elucidativo da distinção entre eficácia e efeito, e, por conseguinte, para que se saiba se convivem no conteúdo da mesma sentença várias eficácias, ou apenas uma eficácia preponderante (força) e vários efeitos - que corresponderiam às eficácias imediata, mediata e mínimas -, os quais efeitos, ao fim e ao cabo, como deixou dito, são classes de eficácia.

Contudo, permanece implícito que a classificação quinária das ações continuará a nortear-se pela preponderância de um dos cinco elementos, ou dos cinco qualificativos já mencionados, sem porém deixar de ser apontado (sic) "pelo menos, o segundo elemento preponderante, para que se ressaltem os diferentes efeitos da sentença" (grifou-se).

Ora, até esse ponto, o elemento preponderante era tido como a força, a qual classificaria a ação e a respectiva sentença, que, além dela, força, haveria de também possuir uma eficácia imediata e outra mediata. Agora, porém, passa a existir um segundo elemento preponderante, que "ressalta" um outro efeito da sentença, mas que pode, aparentemente, não mais ser, este efeito, a outrora eficácia imediata.

Não obstante a perplexidade que tal afirmação possa causar ao leitor, retorna nosso autor ao tema e considera proveitoso "denominar-se cada sentença pela sua força e por seu efeito imediato," algo, todavia, que somente poderá ser alcançado a posteriori em função do peso do elemento declarativo constante em cada sentença.
E, por fim arremata, dizendo que “a)...o peso de eficácia das ações e das sentenças é constante, b) que há cinco elemen. tos que compõe o peso, em ordem decrescente, chamando-se força ao primeiro, c) que é preponderante e dá a classe à ação ou à sentença, e d) que o segundo (eficácia imediata) e o terceiro elemento (eficácia mediata) são de importância considerável" (grifos nossos).

Diante da fluidez dos conceitos, da complexidade e importância do tema, impõe-se ùm parêntese neste ensaio, para melhor reflexão sobre o sentido de certas palavras-chave, usadas por PONTES DE MIRANDA, no transcurso de seu Tratado.

05. É por demais sabido que linguagem é um sistema de símbolos ou de signos, voluntariamente produzidos e convencionalmente aceitos, mediante o qual o homem se comunica com seus semelhantes, expressando suas idéias, sentimentos e desejos.

A linguagem ideal seria aquela em que cada palavra (significante) designasse ou apontasse apenas uma coisa, correspondesse a uma só idéia ou conceito, tivesse um só sentido (significado). Como tal não ocorre em nenhuma língua conhe. cida, segundo dizem os estudiosos, as palavras são, por natureza, enganosas porque polissêmicas. Muitas constituem mesmo uma espécie de constelação semântica, como é o caso, quanto aos exatos conceitos de eficácia e de efeito.

Por essas razões, as palavras são elos numa cadeia de idéias e intenções, interligadas umas às outras por íntimas relações de sentido; dissociá-las da frase é desprovê- 
las de seu significado contextual. A imprecisão do sentido das palavras, que torna difícil ou às vezes impossível a compreensão entre os homens, decorre principalmente da falta de um referente objetivo, pois é somente o mundo real, concreto, que dá à linguagem significação específica, clara e precisa.

Essa precisão, clareza e objetividade é que dará rigor à linguagem a fim de que o conhecimento humano sobre o qual versa assuma status de cientificidade. Dessa for$\mathrm{ma}$, conceito científico seria aquele advindo de conjunto de regras que estabelecesse o uso normal de uma palavra de maneira tal que pudesse ser seu entendimento perfeitamente comunicável intersubjetivamente sem graves perigos de mal-entendidos. A objetividade estaria, destarte, na intersubjetividade do significado compreendido das palavras usadas no discurso.

Basta consultar qualquer dicionário da língua portuguesa para dar-nos conta de que eficácia, em sentido corrente, popular ou erudito, é a qualidade ou a propriedade do que é eficaz. Eficaz é aquilo que produz o efeito desejado, sendo efeito, finalmente, entre as quase duas dezenas de acepções semânticas do vocábulo, sinônimo de eficácia.

Todavia, esse entendimento não contenta as exigências teoréticas da comunidade jurídica nacional, por não contemplar toda a gama das sutilezas e nuances com que ela pode e deve ser empregada no discurso dogmático.

Sendo assim, procuraremos reler o mestre e, em o fazendo, encontrar a linha mestra de seu pensamento, o preciso significado intencional das palavras por ele usadas. Todavia, antes de concluirmos este trabalho a respeito do convívio de várias eficácias no conteúdo da sentença, vejamos, à vol d'oiseau, qual o uso corrente, que a comunidade jurídica brasileira, já conforme com uma mentalidade comum firmada no transcurso do tempo, não só pelo uso continuado desse novo paradigma definido na teoria quinária das ações, como também pela extensão dos poderes de que se encontra investido o juiz em nosso mundo jurídico - em função daquele ecletismo que aludimos nas primeiras linhas desta exposição -, faz dos vocábulos: eficácia e efeito.

JOSÉ CARLOS BARBOSA MOREIRA, por exemplo, define eficácia como sendo a palavra usada, na linguagem jurídica, para "designar a qualidade do ato, enquanto gerador de efeitos"(grifou-se). E acrescenta que "menos freqüente é o uso de eficácia como sinônimo de efeito".

Em obra anterior, afirmara que (sic) "a sentença é dotada de certa eficácia, designando-se neste termo a aptidão, in abstracto, para surtir os efeitos próprios...A questão muda de aspecto...quando nos interessamos pelo efeitos que esta ou aquela sentença é capaz de produzir in concreto"(grifou-se).

Releva salientar, por ser por todas as razões pertinente ao tema estudado, o uso de que fez o anteprojeto do Código de Processo Civil, elaborado pelo então Ministro da Justiça, ALFREDO BUZAID, quando definia, no artigo 471 , a coisa julgada material, como (sic) "...a eficácia, que torna imutável e indiscutível o efeito da sentença..." (grifo nosso).
OVÍDIO A. BAPTISTA DA SIL. VA, por sua vez, seguidor confesso da doutrina de PONTES DE MIRANDA, faz uso sinônimo de ambas as palavras, algo que facilmente se depreende por simples leitura de sua obra, em particular daquela em que trata de "Sentença e Coisa Julgada", pinçando-se exemplos ao acaso, diz ele (sic): "A tal eficácia (em ação de despejo), chama-se de efeito executivo da demanda...De igual modo o efeito executivo da demanda do artigo 641 do Código de Processo Civil é eficácia interna..." (grifou-se).

Ao mesmo tempo, porém, rest incontroverso, pelo exemplo infra colhido na mesma obra, que este autor, em especial no tocante à classificação das sentenças̀, à qual adota e se reporta, admite a existência de várias eficácias em uma mesma sentença, in verbis, "Os problemas atinentes a este vastíssimo tema ligado à classificação das sentenças, pelas suas respectivas eficácias não poderá, como é natural, ser enfrentado agora..."(grifo nosso).

Ponto de vista esse corroborado pela afirmação que faz logo em seguida, onde acusa de grave erro a pressuposição de corrente doutrinária que acolhe a idéia (sic) “...de que em cada sentença tenha uma só eficácia, quando eles próprios (processualistas) não negam que muitas sentenças, pelo menos apresentam múltiplos efeitos". (grifou-se).

Já ARAKEN DE ASSIS, na obra aqui citada, após realçar o mérito de PON. TES DE MIRANDA em fazer presente a existência de uma eficácia declaratória, em uma mesma sentença, a par de outras eficácias (ou forças), com "cargas mitigadas mas ainda assim comprovadamente presen tes em cada caso", dá exemplo de sentença em ação de separação, onde alinha todas as eficácias possíveis: preponderante, imedia ta, mediata e mínimas, sem mencionar distinções nem fazer menção a efeitos.

Escreve ele in verbis: “...na ação de separação judicial (eficácia principal: constitutiva), o órgão jurisdicional desfaz a relação jurídica nos efeitos que a lei autoriza e manda seja procedida a averbação no assento de casamento (eficácia secundária: mandamental); esta sentença, ainda, examina previamente a própria relação de casamento (eficácia secundária: declaratória) e dispõe sobre a partilha de bens (eficácia secundária: executiva).

Dos processualistas compulsados, muito embora não tenhamos efetuado pesquisa exaustiva, saliente-se o que pensa a respeito o professor CARLOS ALBERTO ALVARO DE OLIVEIRA, que faz nítida distinção entre os dois termos, na procura de fixar o exato significado de cada um deles, ao tratar de tutela de urgência.

Para ele, in verbis, "A eficácia diz res. peito ao conteúdo do ato jurídico, aos ele. mentos que o compõem; os efeitos à produção de alterações no mundo sensível, como conseqüência de eficácia. A condenação, por exemplo, constitui eficácia da sentença condenatória, elemento de seu conteúdo; a possibilidade de execução ou a própria execução, efeito executivo dela de. corrente. Verifica-se, portanto, íntima re. lação condicionante entre essas duas categorias, pois não pode haver por hipóte. se efeito sem eficácia, determinando o conteúdo desta a conseqüência verificada com aquele". (grifos do Autor) 
06. Armado dessas elucidações e esclarecimentos, podemos retomar, para concluir, o tema principal do estudo, qual seja o de verificar se, no conteúdo da sentença, convive uma só eficácia, ou convivem várias; se em suma assiste razão a PONTES DE MIRANDA no atribuir diversas eficácias a uma só sentença.

Cremos, a esta altura, poder dizer sem receios de errar que a antinomia a qual nos conduziu a exposição de PONTES DE MIRANDA é aparente, ao não precisar os conceitos com que trabalha com o devido rigor indispensável a sua inteligibilidade, acarretando com essa fluidez conceitual uma conseqüente imprecisão no entendimento sobre se a sentença contém uma só ou várias eficácias.

Do ponto de vista de PONTES DE MIRANDA, que fez escola entre nós com esse novo paradigma, a resposta há de ser afirmativa. A sentença comporta várias eficácias.

Quanto a assistir a ele razão, a análise do tema ultrapassaria os limites deste trabalho, contudo, ressalte-se, corrente doutrinária respeitabilíssima acredita que não. $E$, ao que tudo indica, conta ela com interpretação de verossimilhança mais provável. A resposta nesse sentido, pois, haveria de ser negativa. A sentença comportaria uma eficácia.

Eficácia é termo genérico, lato, que engloba o conceito de efeito, contido na sentença. Neste ponto talvez fosse conveniente retroceder alguns passos em nossa exposição, àquela parte onde falamos sobre o sentido das palavras.
Por mais variados que os sentidos sejam, situam-se sempre em dois planos: o da denotação e o da conotação. O primeiro é o elemento estável da significação de uma palavra, aquele não subjetivo e analisável fora do contexto. A conotação traz em si elementos subjetivos, que variam conforme o contexto do discurso, isto é, quando a significação da palavra não é a mesma para todos os membros da comunidade (jurídica), e não o é em virtude de a interpretação que cada um dos membros a ela dá, não é necessariamente igual aos dos demai membros deste mesmo grupo, e, sobretu do, porque a palavra não remete a um objeto concreto do mundo extralingüístico, mas apenas, pragmaticamente, sugere ou evoca, por associação, uma outra idéia de ordem abstrata.

Cremos, pois, ser legítima a assertiva de que o nomen iuris próprio e adequado, para determinar a conseqüência jurídicoprocessual advinda do conteúdo da sentença, é o de eficácia, donde provirão os correspondentes efeitos.

Grosso modo, parece ser essa a for ma mais consoante com a lógica do razoável de que nos fala RÉCASENS SICHES, para se entender e, sobretudo, para se sair e escapar deste intrigante jogo de palavras apreendendo assim o real sentido de eficácia e efeito, existentes no conteúdo de cada sentença.

O que leva a primeira corrente, liderada por PONTES DE MIRANDA, a supor que qualquer sentença possui várias eficácias, é o fato de que, tanto quanto as ações constitutivas e as condenatórias, as respectivas sentenças contêm também o elemento declaratório, olvidando, talvez, que a eficácia provinda do conteúdo de cada uma delas e, conseqüentemente, efeitos, não advém daí, mas da conseqüência necessária e suficiente (pois que quanto a isto não há discordância) de serem elas, sentenças, atos jurídicos que lhes define a natureza jurígena. Os efeitos daí advindos, os efeitos provenientes da eficácia de cada sentença, são condicionados pelos elementos do conteúdo da sentença, para produzirem conseqüências na realidade fáctica da vida, efeitos, aliás, que, como disse o autor, são também eficácia.

Após essas considerações e comentários, e, sobretudo, após ter-se laborado nas devidas distinções das diferentes iděias empregadas pelo gênio que foi o saudoso mestre e jurista, ao fim e ao cabo, cremos poder afirmar, em consonância com a corrente contrária à de PONTES DE MIRANDA, sem rebuços, que, no conteúdo da sentença, exsurge apenas uma eficácia, aquela preponderante, a força, a que qualifica o tipo de tutela jurisdicional prometida pelo Estado à parte ofendida em seus interesses, e dela, os decorrentes efeitos.

Contudo, ainda há algumas últimas observaçōes a serem feitas, pois as palavras, pelo visto, são frágeis instrumentos, mas os únicos com que contamos para transmitir nossos sentimentos, desejos e idéias. Não poucas vezes, apresentam-se ilusórias e enganosas, levando-nos, sem querer, a interpretações ou conclusões indesejadas.

Não desdizemos o anteriormente dito, a respeito de emergir do conteúdo da sentença, nos estritos termos jurídico-processuais, em que colocamos o âmbito deste estudo, uma eficácia que a classifica, dirimente da lide, e satisfativa dos interesses em conflito, através da tutela jurisdicional prestada pelo Estado.

Todavia, poder-se-ia ainda indagar, se, por acaso, seria lícito afastar o que está posto no artigo 467 do Código de Processo Civil, quando denomina a coisa julgada material de eficácia que a torna a sentença imutável e indiscutível. Constituir-se-ia, desta maneira, a coisa julgada material mais uma eficácia, a ser acrescida àquela que classifica a sentença, ou deveria ser ela interpretada tão-só e simplesmente como um efeito?

Esse questionamento não apresenta nenhum mérito inovador, pois o artigo 467 do Código de Processo Civil tem sido motivo de inúmeras e acerbas críticas de processualistas de tomo. Fica, contudo, colocada a ressalva, uma vez que abordagem mais alongada a respeito, aqui e agora, transbordaria aos limites impostos no início do trabalho.

Na seqüência do exposto vêm a ponto nossas derradeiras considerações e comentários a propósito da teoria quinária da ação e da eficácia da sentença, da lavra do conceituadíssimo jurista que foi PONTES DE MIRANDA.

Concluímos na certeza de que, para ele, convivem, no conteúdo da sentença, várias eficácias. Para outros, não menos ilus. tres e distinguidos, uma só, que a classifica e da qual decorrem vários efeitos.

Finalmente, observamos que, na "co. munidade comunicativa", jurídica - fora dos estritos limites da teoria do processo -, es- 
tes dois termos, eficácia e efeitos - mesmo que impropriamente a nosso juízo - são usados lato sensu, como correlatos, sem que, todavia, o contexto do discurso deixe de ser compreendido pelo endosso intersubjetivo dado pelos membros do auditório a que se destinam, com a óbvia ressalva de que sejam empregadas com rigor científico.

Porto Alegre, 19 de julho de 1999.

\section{Bibliografia}

ALVARO DE OLIVEIRA, Carlos Alberto. Perfil Dogmático da Tutela de Urgência, Separata. Vol. 342, Forense, 1999.

.Do Formalismo no Processo. Editora Saraiva, 1997. Araújo dos Santos, Francisco. Crítica Epistemológica, trabalho inédito, 1999.

Episteme e Paradigma: crítica a Thomas Kuhn à luz do caso Galileu. Série de documentos para estudo da Escola de Administração da UFRGS, Outubro de 1997.

A Decisão Empresarial: Aspectos Subjetivos e Coletivos da 'Razoabilidade Criativa'. Mais uma lição de Feitas para Durar. Série Documentos para Estudo. Programa de Pós-Graduação em Administração da UFRGS, Escola de Administração, 1998.

ASSIS, Araken de. Sobre o Método em Processo Civil. Instituto dos Advogados do Brasil, 60 Anos de Existência. Porto Alegre, 1986, pp. 229/246.

BAPTISTA DA SILVA, Ovídio. Sentença e Coisa Julgada. Ensaios, Sergio Antonio Fabris Editor, 1979.

Direito Subjetivo, Pretensão de Direito Material e Ação. Ajuris, vol. 29, pp. 99/126.
BAPTISTA, J. Machado. Introdução ao Direito e ao Discurso Legitimador. Almedina: Coimbra 1997 (10ª reimpressão).

BARBOSA MOREIRA, José Carlos. Coisa Julgada e Declaração. Temas, $1^{\text {a }}$ série, pp. 81 e ss.

Conteúdo e Efeitos da Sentença. Variações sobre o Tema. Ajuris, no 35, 1985, pp. 204/212.

Eficácia da Sentença Autoridade de Coisa Julgada. Ajuris, no 28 , 1983, pp. 15/31.

BOBBIO, Norberto. Contribución a la Teoria de Derecho. Madrid: Ed. Alfonso Luiz Miguel, 1990

BUZAID, Alfredo. Mandado de Segurança. Vol. I, Editora Araiva, 1989

CAPELLETTI, Mauro. Repudiating Montesquieu. The Expansion and Legitimacy of Constitutional Justice. In Revista de la Facultad de Derecho de Mexico. Tomo XXXVI, Julio/ Deciembre 1986.

CIRNE-LIMA, R. V. Carlos. Dialética e Evolução. In Finitude e Transcendência, Festschrift em Homenagem a Emildo Stein. EDIPUCRS, 1996, pp. 47/80.

DINAMARCO, Cândido Rangel. Doutrina Nacional - Processo Civil - O Conceito de Mérito em Processo Civil.

FALZEA, Ângelo. Enciclopedia del Diritto, verbete: Efficacia Giuridica. Sez. V, itens 47, 48, 49 e 50.

GARCIA, Othon M. Comunicação em Prosa Moderna. 17. ed., FGV Editora, (2 reimpressão), 1997.

GRINOVER, Ada Pellegrini. Notas ao $\S 1^{\circ}$ Eficácia e Autoridade da Sentença. 3. ed., Fo rense, 1984.

KIRCHMANN, J. H. VON. La Jurisprudencia no es Ciencia. tradução espanhola de
António Truyol y Serra, $2^{\mathrm{a}}$ edição com uma nota adicional. Coleccion Civitas, Instituto de Estudios Politicos, Madrid: 1961.

LACERDA, Galeno. Eficácia da Prestação Jurisdicional no Atendimento às Demandas Sociais. Ajuris, no 59, pp. 49 a 61.

LIEBMAN, Eurico Tullio. Eficácia e Autoridade da Sentença. 3. ed., Forense, 1984.
MANGABEIRA, João Rui. O Estadista da República. Vol. no 240, 1. ed., tiragem de 300 exemplares, assinada pelo Autor, 1943.

PONTES DE MIRANDA. Tratado das Ações Vol. I, II e III. Editora Revista dos Tribunais Ltda., 1971.

WATANABE, Kazuo. Da cognição no Processo Civil. Editora Revista dos Tribunais, 1987.

Revista da Faculdade de Direito da UFRGS, v. 18, 2000 